\title{
DILEMA MORAL NA EDUCAÇ̃̃O INFANTIL: GENEROSIDADE OU JUSTIÇA?
}

ROSANA AKEMI KAWASHIMA

RAUL ARAGÃO MARTINS

\section{RESUMO}

O objetivo deste trabalho é investigar os juízos a respeito da virtude generosidade ou justiça de professores da educação infantil e compará-los com os das crianças. Foram entrevistados 26 professores e 90 crianças de 4, 5 e 6 anos de idade desse nível de ensino. 0 instrumento utilizado foi um dilema moral em que a protagonista da história teria de optar entre dar um prêmio para a criança que fez o desenho mais bonito (justiça) ou para a criança que estava triste (generosidade). Os resultados indicam que a justiça é a virtude mais valorizada pelas professoras e que já é valorizada pelas crianças, podendo ser uma necessidade para elas. E a generosidade é mais valorizada pelas crianças do que pelas professoras.

PALAVRAS-CHAVE GENEROSIDADE • JUSTIÇA • EDUCAÇÃO INFANTIL • VALORES MORAIS. 


\section{RESUMEN}

El objetivo de este trabajo es investigar los juicios sobre la virtud de generosidad o de justicia de profesores de educación infantil y compararlos con los juicios de los niños. Se realizaron entrevistas con 26 profesores y 90 niños de 4, 5 y 6 años de ese nivel de enseñanza. Se utilizó un instrumento que planteaba un dilema moral en el que la protagonista de la historia tenía que optar entre darle un premio al niño que hubiera hecho el dibujo más bonito (justicia) o al niño que estaba triste (generosidad). Los resultados indican que la justicia es la virtud más valorada por las profesoras, y también es valorada por los niños para quienes puede ser una necesidad. La generosidad, a su vez, es más valorada por los niños que por las profesoras.

PALABRAS CLAVE GENEROSIDAD • JUSTICIA • EDUCACIÓN INFANTIL • VALORES MORALES.

\section{ABSTRACT}

The aim of this study is to investigate the judgments about the virtue of generosity or justice by teachers in early childhood education and compare their judgments with the children's judgments about generosity or justice. We interviewed 26 teachers and 90 children aged 4, 5 and 6 years at this level of education. The instrument used was a moral dilemma in which the protagonist of the story would have to choose between giving a prize to the child who drew the most beautiful picture (justice) or to the child who was sad (generosity). The results indicate that justice is the virtue most valued by teachers and that it is already valued by children and may be a need for them. And generosity is valued more by children than by teachers.

KEYWORDS GENEROSITY • JUSTICE • EARLY CHILDHOOD

EDUCATION • MORAL VALUES. 


\section{INTRODUÇÃO}

A moral e a ética têm sido foco de muitos estudos na psicologia moral. Para Marilena Chauí (2004), moral denota "costume" ou comportamento estabelecido por uma sociedade, e ética significa "caráter de alguém" ou o conjunto de normas formado por uma sociedade para ajustar a conduta dos indivíduos. Assim, segundo a autora, as palavras moral e ética referem-se basicamente ao conjunto de costumes tradicionais de uma sociedade que, como tais, são considerados valores e obrigações para a conduta de seus membros. Pelos possíveis sentidos e usos atribuídos a esses conceitos, eles são frequentemente empregados como sinônimos.

Para La Taille (2006b), de modo geral, na literatura, as caracterizações da moral se referem aos valores, princípios e regras que uma determinada sociedade ou indivíduo legitima, e a palavra ética traz referência à reflexão sobre tais valores, princípios e regras, o que significa que não são necessariamente sinônimos. O que melhor caracteriza a moral, segundo esse autor, é a dimensão do dever, enquanto a ética diria respeito à dimensão da felicidade. 
La Taille (2006b) associa a moral à pergunta: como devo agir? Esta se refere às nossas obrigações e aos nossos deveres como cidadãos que convivem e agem segundo certas leis. No entanto, surge outra questão: o que faz os sujeitos agirem por dever? Para ele, é o sentimento de obrigatoriedade que legitima a ordem; é se sentir obrigado a agir por dever que define agir moralmente. Todavia, o sentimento de obrigatoriedade tem relação com o querer, pois somente se sente obrigado a agir moralmente quem assim o quer. Mas como identificar quem quer ser moral? Ou ainda, por que algumas pessoas querem agir moralmente e outras não?

Os seres humanos querem muitas coisas ao mesmo tempo e têm muitas vontades, diz La Taille; há quereres conflitantes e diferentes, uns morais e outros não morais. Dentre todos esses quereres, somente se agirá moralmente se o querer ser moral for mais forte que os outros quereres, ou seja, esse querer agir por dever precisa ser mais forte do que qualquer outro querer para ser moral. Nesse contexto, as pessoas que agem por dever o fazem porque acreditam que agindo dessa forma fazem o bem (LA TAILLE, 2006b).

Esse querer agir bem é o que se chama de ética. Enquanto na moral prevalecem os deveres, a ética está ligada à qualidade de vida e às reflexões de "vida boa" ou "vida que vale a pena ser vivida”, inspirada na felicidade. Para então responder à pergunta ligada à ética (“que vida eu quero viver?"), La Taille (2006b) explica que ela reside na busca de um sentido que faça as pessoas quererem ser melhores, na tomada de consciência de si e no desejo de superação de si, de seus próprios limites, e na necessidade de enxergarem a si próprios como de valor. Essa tendência de "expansão de si próprio" incide sobre o valor do eu (LA TAILLE, 2006b).

Para Tognetta (2009a, p. 23):

[...] a moral representa um conjunto de regras que nos permite pensar como devemos agir para o bem alheio. A moral, portanto, funda um sentimento de obrigatoriedade que exige que busquemos não qualquer conteúdo, mas sim um conteúdo de justiça, de generosidade, de honestidade e tantos outros valores morais que poderíamos pretender. $\mathrm{E}$ quem orienta a moral? É sem dúvida a nossa capacidade 
de discernir entre o bem e o mal, entre o certo e o errado, ou seja, a tomada de consciência. [...] Assim, se tomar consciência de um dever moral não é suficiente para que as nossas ações sejam justas, generosas, é porque assim é preciso que queiramos fazer o bem ao outro, mas se isso for o que nos fizer, também, nos sentirmos bem.

Portanto, para esse autor, as ações morais e o modo como estas se tornarão morais dependem da correspondência entre as imagens de si e os conteúdos morais elas associados; as imagens que alguém faz de si, que são os investimentos afetivos e os valores integrados à identidade, devem estar relacionadas aos valores morais para o sujeito querer agir moralmente. Desse modo, para que o sujeito respeite o outro e aja moralmente, é preciso que as representações de si tenham valor, ou seja, somente quando se dá valor a si mesmo se passa a valorizar o outro e a respeitá-lo. As representações de si são sempre valorativas e, portanto, são investimentos afetivos. Segundo La Taille (2006b), quando esses valores morais estão associados às representações de si, eles são denominados virtudes morais.

O filósofo francês André Comte-Sponville, na obra Pequeno tratado das grandes virtudes, explica que virtude "[...] é uma força que age, ou que pode agir [...], é poder, mas poder específico [...], a virtude do ser é o que constitui seu valor, em outras palavras, sua excelência própria” (COMTE-SPONVILLE, 1995, p. 8). Por exemplo, a virtude da faca é cortar, a do remédio é tratar e a do homem é querer e agir humanamente. Para o autor, todas as virtudes exercem suas funções específicas e isso basta para os objetos e animais, mas não para o homem, não para o homem virtuoso: "A virtude de um homem é o que o faz humano, ou antes, é o poder específico que tem o homem de afirmar sua excelência própria, isto é, sua humanidade" (COMTE-SPONVILLE, 1995, p. 8). Em suma, é o que faz um homem virtuoso.

Na Ética a Nicômaco, Aristóteles (2001) apresenta a virtude como uma prática que corresponde à forma mais plena da excelência moral; ela seria, antes de tudo, uma disposição de caráter. Para exercê-la, seria necessário conhecer, julgar 
e discernir. Mas esse conhecimento não é necessariamente teórico; a virtude é construída pelo hábito, pela ação propositadamente exercitada e repetida. O modo de agir perante os outros, perante a si próprio, perante os que são próximos, perante a humanidade, de forma virtuosa, é próprio do homem que se preocupa com a ética.

Assim, o que Aristóteles quer dizer, na interpretação de Tognetta, é que a "virtude é a nossa própria condição humana, já que é desejo de superação, de chegar a uma perfeição que nos permite a excelência. São as virtudes, portanto, nossas excelências, aquelas que nos traduzem a nossa mais bela condição de homens" (TOGNETTA, 2007, p. 10). Logo, as virtudes dizem respeito às características do ser, que nos qualificam enquanto seres humanos, mas elas não somente se referem às qualidades de cada pessoa, como também apontam para qualidades apreciadas, admiradas e almejadas, como esclarece La Taille (2000). Comte-Sponville (1995, p. 9) acrescenta que, para Aristóteles, a virtude "é uma disposição adquirida de fazer o bem, [...] não o bem absoluto que bastaria conhecer, não o bem para se contemplar, mas para se fazer pelo próprio esforço".

Quando se fala que virtude é uma disposição e que exige esforço, isso significa que ela não é obrigatória e, portanto, não é dever buscar a excelência ou querer ser melhor; é preciso querer ser virtuoso. Assim, a pessoa virtuosa é uma pessoa boa que age e quer o bem para si e para os outros.

Das muitas virtudes, é consenso entre estudiosos, sobretudo na psicologia moral, como em Piaget (1994) e Kohlberg (1992), que o valor moral mais importante é a justiça. Para Comte-Sponville (1995), a justiça é a virtude mais completa, a mais geral; ele lembra Aristóteles, que a considera a mais perfeita das virtudes, pois supõe a igualdade dos direitos, sejam eles juridicamente estabelecidos ou moralmente exigidos. Para La Taille (2006b), os dois princípios que imperam na justiça são: a igualdade, que estabelece que todos devem ser tratados de forma igual e sem privilégios; e a equidade, que, reconhecendo as diferenças entre os seres humanos, exige que sejam tratados de forma diferente.

Mas, será que a justiça, vista como virtude cardeal norteadora das relações sociais, que considera o direito de ser 
tratado e o dever de tratar os outros de forma justa, bastaria para agir moralmente? As virtudes que não implicam somente direitos e deveres não nos qualificariam como morais e éticos? A justiça é, com certeza, a virtude que toda sociedade almeja, mas, como diz Comte-Sponville (1995, p. 93), "a doçura e a compaixão não fazem as vezes da justiça, nem assinalam seu fim; elas são antes sua origem".

Assim, para ser virtuoso pode-se dar ao outro o que lhe falta ou, ainda, dar ou fazer algo que lhe dê prazer ou que lhe traga felicidade, ou seja, é preciso querer fazer algo para o bem e, para isso, é necessário estar bem consigo mesmo, do ponto de vista das disposições para ser solidário, tolerante, generoso, sem nenhuma exigência como retorno, e por isso as virtudes apontam para a excelência (TOGNETTA; ASSIS, 2006).

A inclusão do estudo de outras virtudes é fundamental para que a justiça deixe de ocupar um lugar privilegiado como virtude exclusiva para o estudo da moral. Segundo La Taille (2009), há alguns motivos para que outras virtudes não sejam rejeitadas: a) algumas virtudes originam outras e por isso participam da gênese da moralidade, como é o caso da polidez; b) outras virtudes que dizem respeito às relações interpessoais harmoniosas e respeitosas, embora não exigidas e não absolutamente boas, são consideradas um dever para quem as incorpora para si, e por isso pertencem ao plano moral, como é o caso da fidelidade; c) certas virtudes não são morais em si, mas participam da efetivação de outras, como é o caso da coragem; d) as crianças percebem as virtudes em seu meio social desde cedo e já fazem avaliações sobre as qualidades das pessoas.

Em presença desses argumentos, foi escolhida, além da justiça, a generosidade como virtude contemplada para este estudo. E os motivos serão explicados a seguir. Piaget (1994) postulou dois tipos de respeito entre as pessoas: respeito unilateral e respeito mútuo. O primeiro é regido pela moral da obediência e da autoridade; o segundo, pela moral da reciprocidade e da cooperação. Na educação infantil, na relação entre a criança e o adulto, o respeito pela autoridade tem primazia. Um dos objetivos da autoridade é cuidar da criança pequena em todas as suas dimensões: afetiva, intelectual, 
moral, física, nutricional etc. Contudo, o cuidar é muitas vezes visto com preconceito e deixado em segundo plano na educação. Tem-se buscado cada vez mais a valorização do ato de cuidar na educação infantil, e foi em Montenegro (2001) que surgiu o sentido moral da palavra cuidar associado à virtude generosidade, o que, portanto, engrandece seu sentido como uma entre as virtudes morais. $\mathrm{O}$ primeiro argumento da escolha do tema é devido ao cuidar ser uma das principais funções do professor de educação infantil e, este, pertencendo ao campo moral, torna-se função nobre para o professor que trabalha com a criança pequena. Além disso, a generosidade compreende a função de cuidar e educar, tornando possível a justaposição entre a inteligência e a afetividade, pois, para ser generoso, é preciso sentir simpatia por uma pessoa, o que requer a descentração para poder avaliar (pensar, raciocinar) se a pessoa merece esse sentimento (de simpatia) e, assim, agir generosamente.

A esse respeito, La Taille comenta a seguinte frase extraída do livro 0 juízo moral na criança, de Piaget (1994): “É quando a criança habitua-se a agir do ponto de vista dos próximos, e preocupa-se mais em agradá-los do que a eles obedecer, que ela chega a julgar em função das intenções" (LA TAILLE, 2000, p. 105, grifo do autor). Para ele, essa frase, além de explicar a passagem da moral heterônoma para a moral autônoma, fala mais de generosidade do que de justiça quando emprega o verbo agradar. La Taille levanta a hipótese de que a generosidade precede a justiça, moralmente falando, do ponto de vista cronológico. Em 2006, o autor realizou uma pesquisa para averiguar a gênese da generosidade na moralidade e concluiu que "a generosidade não somente é virtude presente no início da gênese da moralidade, como é mais bem assimilada e, portanto, integrada à consciência moral, do que a justiça nesta mesma fase do desenvolvimento" (LA TAILLE, 2006a, p. 16). Isso reforça nossa escolha por tratar da virtude generosidade na educação infantil, pois ela está presente na relação da autoridade com as crianças e também entre elas.

Mas o que é generosidade? Nas palavras de La Taille (2006b, p. 62): "O ato de generosidade favorece quem é por ele contemplado, não quem age de forma generosa. É por ser a 
generosidade a inteira dedicação a outrem que digo que ela traduz plenamente o altruísmo". É o que está em jogo na generosidade e o que a diferencia da justiça. Comte-Sponville (1995, p. 97) diferenciou justiça e generosidade dizendo que:

[...] ambas se referem às nossas relações com outrem, mas a generosidade é mais subjetiva, mais singular, mais afetiva, mais espontânea, ao passo que a justiça, mesmo quando aplicada, guarda em si algo mais objetivo, mais universal, mais intelectual ou mais refletido. A generosidade parece dever mais ao coração ou ao temperamento; a justiça, ao espírito ou à razão.

Comte-Sponville (1995) afirma ainda que o indivíduo generoso é aquele que age não em conformidade com a lei, com alguma indicação estruturada e predeterminada, mas se refere à liberdade, bondade e magnanimidade. Acrescentam Tognetta e Assis (2006) que ser generoso requer uma disposição de caráter que não exige algo em troca, porque, a princípio, a ação já é disponível e pressupõe que, ao sujeito que age, não lhe causa mal algum. Mas o conceito de generosidade não poderia ser confundido com o de solidariedade? Alguma similaridade com a solidariedade pode ocorrer, contudo, explica Comte-Sponville (1995):

[...] a solidariedade é, antes de mais nada, o fato de uma coesão, de uma interdependência, de uma comunidade de interesses ou de destino. Ser solidário, nesse sentido, é pertencer a um mesmo conjunto e partilhar, consequentemente - quer se queira, quer não, quer se saiba, quer não -, uma mesma história. (p. 98)

Portanto, na solidariedade existe o autointeresse, como na justiça, já a generosidade vai além do interesse. La Taille (2000) afirma que uma pessoa não se beneficia materialmente ao ser generosa, mas pode experimentar prazer ou felicidade com seu ato. O que há de característico na generosidade é que a retribuição é inesperada, não é exigida, não é garantida quando se dá. Mas será que quando uma pessoa é generosa não se espera nada em troca? Não se espera retribuição por um ato de generosidade? La Taille (2000) afirma 
que não há interesse próprio em ser generoso e, se houver, não haverá generosidade.

Além do não autointeresse envolvido, a generosidade também não pode ser confundida com o amor, pois, para Comte-Sponville (1995), a generosidade nasce exatamente pela falta de amor, e quando há amor, é fácil dar algo a quem se ama; contudo, a generosidade nos incita a dar algo justamente a quem não amamos por necessitarem, pois o amor não está em nosso poder, mas a generosidade, sim; ela depende da nossa vontade. "Portanto, não se trata de amar, mas de agir como se amássemos" (COMTE-SPONVILLE, 1995, p. 108). Assim, o amor não se comanda, a generosidade, sim; ela depende do que nós queremos, ela é definida pelo nosso desejo, desejo de amor, desejo de alegria, desejo de partilha, que nos eleva em direção aos outros, enfim, é a virtude do dom. La Taille (2001), por sua vez, afirma que a generosidade, muitas vezes, carece de esforço, sacrifício e reflexão, por isso essa virtude aponta para a excelência.

Em estudos sobre a generosidade, tem-se pesquisado principalmente sobre a gênese dessa virtude no universo moral das crianças e adolescentes (LIMA, 2000; DIAS, 2002; VALE, 2006; PINHEIRO, 2009; TOGNETTA, 2009b), da mesma maneira, há pesquisas (LUKJANENKO, 1995; COSTA, 2007; SOEJIMA, 2008; entre outros) que demonstraram a importância da participação dos educadores no desenvolvimento dos juízos morais e na construção da autonomia e do respeito mútuo entre os alunos.

Dessa forma, a ética do cuidado proposta por Gilligan (1982) abriu um novo horizonte para o estudo da moralidade, possibilitando a introdução do altruísmo como elemento significativo ao julgamento moral. Para La Taille (2006b), a compreensão do outro, levando em consideração suas necessidades e sentimentos, é denominada sensibilidade moral. Para o autor, "ela pressupõe a capacidade de ler nas entrelinhas, de interpretar sinais, de perceber a sensibilidade alheia, seus motivos de alegria e de sofrimento" (LA TAILLE, 2006b, p. 90). Assim, a sensibilidade moral fica mais localizada no contexto, nos detalhes, na singularidade das pessoas, o que nos faz pensar que à sensibilidade é necessária uma atitude generosa, 
pois, segundo Lima (2004), o cuidar do outro quase sempre nos convoca a dar mais do que lhe é de direito, portanto, a sermos generosos. Montenegro (2001) encontrou na virtude generosidade o significado mais profundo da concepção de cuidado. Para ela, associar a generosidade à atividade do cuidado tornou possível vislumbrar um processo de educação moral não polarizada entre razão e emoção, incidindo na necessidade de incluir a formação moral na atividade de cuidar desenvolvida pelas educadoras infantis.

Portanto, inserindo tais reflexões na presente pesquisa, o objetivo deste trabalho é investigar os juízos a respeito da virtude generosidade ou justiça de professores da educação infantil, e comparar os juízos a respeito da generosidade ou da justiça dos professores com os das crianças.

\section{MÉTODO}

\section{PARTICIPANTES}

Os participantes da pesquisa foram alunos e professores da educação infantil de quatro escolas municipais de uma cidade de médio porte do interior do Estado de São Paulo. O grupo de crianças selecionadas não poderia frequentar turmas integrais, pois elas interagem com dois professores, um no turno da manhã e outro no turno da tarde, dificultando a escolha e a identificação da criança com o professor, pois, inicialmente, pretendia-se investigar a identificação dos alunos em relação à virtude generosidade de seus professores. As crianças eleitas foram aquelas que obtiveram a autorização de seus responsáveis para participar da pesquisa e elas têm idades entre quatro e seis anos, com amostra de 90 crianças, 30 crianças de cada idade, divididas igualmente por sexo (30 crianças de quatro anos, 15 meninas e 15 meninos; 30 crianças de cinco anos, 15 meninas e 15 meninos; e 30 crianças de seis anos, 15 meninas e 15 meninos). Os professores da pesquisa são todos aqueles que lecionam para as quatro escolas selecionadas e que aceitaram participar da pesquisa, correspondendo ao número de 26 participantes.

A seguir, apresentam-se as características das professoras da pesquisa, por idade, por tempo de serviço e por tipo de 
contratação. Uma observação é necessária quanto ao $1^{\circ}$ ano, série de nível fundamental, mas que consideramos como pertencente à educação infantil. No momento dos contatos iniciais com as escolas e com a Secretaria da Educação, o $1^{\circ}$ ano era ainda considerado antiga pré-escola ou nomeado por algumas escolas como série inicial. Na mudança do ano letivo e, portanto, no início da coleta de dados, a denominação mudou em todas as escolas, mas elas continuaram sendo lecionadas em escolas de educação infantil, que, no momento em que optaram em permanecer com salas de $1^{\circ}$ ano, foram consideradas escolas mistas: infantil e fundamental. Nessa ocasião, nomeamos nossos sujeitos como pertencentes à educação infantil, pois eles mesmos ainda se consideravam pertencentes a esse núcleo (BRASIL, 2006).

A pesquisa revela que $36 \%$ das professoras têm de 20 a 29 anos de idade, $28 \%$ delas têm de 30 a 39 anos, $28 \%$ têm de 40 a 49 anos, $4 \%$ têm de 50 a 59 anos e $4 \%$ têm idade acima de 60 anos. Quanto ao tempo de serviço, 26,9\% delas trabalham de 1 a 5 anos como docentes, 3,8\% trabalham de 5 a 10 anos, $26,9 \%$ trabalham de 10 a 15 anos, $15,4 \%$ trabalham de 15 a 20 anos e $26,9 \%$ trabalham há mais de 20 anos no magistério. Em relação à contratação, 57,7\% delas são contratadas de forma efetiva e $42,3 \%$ são contratadas como temporária no magistério.

\section{PROCEDIMENTOS}

A entrevista clínica piagetiana foi utilizada como método para a coleta de dados (PIAGET, 1975, 1994; DELVAL, 2002). Como instrumento foi aplicada uma história-estímulo no formato de dilema moral, para ambos os grupos, professores e crianças, sendo que para as crianças foi necessária a construção de desenhos ilustrados. A história-estímulo foi construída com seu respectivo desenho ilustrado, um, com personagens femininos, para as meninas e outro, com personagens masculinos, para os meninos. O desenho ilustrado tem a finalidade de contrabalançar o efeito da memorização da história-estímulo, recurso utilizado principalmente com crianças pequenas (MARTINS, 1986; DELVAL, 2002). 
A história-estímulo aborda um dilema moral e o sujeito da entrevista emite uma decisão acerca do que deveria fazer o personagem na situação dada e por que deveria fazer. Na história-estímulo é abordada a escolha da autoridade da sala de aula em agir com justiça ou generosidade com uma criança pequena no ambiente escolar. Esse dilema tem como objetivo investigar sobre o juízo da virtude generosidade de professores e se, quando posta lado a lado com a justiça, ela é valorizada. Eis a história apresentada, seguida das perguntas feitas aos participantes:

Houve um concurso na escola que elegeria o desenho mais bonito. A criança ganhadora receberia um prêmio. O desenho mais bonito foi o do(a) André (Andreia), mas a professora sabia que havia um(a) outro(a) menino(a), o(a) Júlio (Júlia), que tinha perdido o cachorrinho na semana passada. Júlio(Júlia) estava muito triste e a professora ficou em dúvida se deveria dar o prêmio a André (Andreia) (justiça) ou a Júlio (Júlia) (generosidade). Ela resolveu dar o prêmio a Júlio (Júlia).

1. Você acha que a professora fez certo ou errado?

2. Por quê?

3. E se fosse a sua professora (você), ela ia dar o prêmio para quem?

4. Por quê?

Todas as entrevistas foram individuais e gravadas em áudio e, logo após, foram transformadas do material oral ao escrito. Assim, terminada a fase de transcrição, foi realizada a leitura desse material a fim de categorizar os dados para sua posterior análise. Para o levantamento dos dados da entrevista clínica piagetiana, foram elaboradas as categorias para as respostas dos participantes. Por fim, concluída a categorização dos dados da entrevista, estes foram inicialmente digitados em uma planilha eletrônica e exportados para um programa de análises estatísticas (SPSS, 2011). Por meio desse programa, foram realizados cálculos das frequências e porcentagens das variáveis; contudo, a análise quantitativa foi utilizada como referência para auxiliar na apresentação e na discussão dos resultados, pois foi priorizada a análise qualitativa. 


\section{RESULTADOS E DISCUSSÃO}

A maioria das docentes $(84,6 \%)^{1}$ considera errada a atitude da professora da história e a maior parcela $(53,8 \%)$ justificou sua resposta pela categoria "combinados", mas também foram representativas as categoria "merecimento" $(23,1 \%)$ e "sem sentimento" (11,5\%). Por outro lado, a minoria $(27,8 \%)$ das crianças considera errada a atitude da professora da história e fundamentou ${ }^{2}$ suas respostas em consonância com a categoria "merecimento" $(16,7 \%)$.

Dentre as professoras que consideram errada a atitude da professora da história, 53,8\% justificaram que as ações das professoras somente devem se basear no que foi "combinado", o que foi explicado por elas como "combinado é combinado", ou seja, o que elas decidem, dizem ou combinam com a classe não se altera, pensam elas, e se "voltam atrás", acham que sua autoridade ficará abalada, principalmente com crianças pequenas.

Tognetta e Vinha (2007) observaram que alguns educadores interpretam os "combinados" de forma reducionista e equivocada e evidenciaram que o processo de elaboração de normas é, muitas vezes, desprovido de fundamentação. Para as autoras, existem as regras negociáveis, em que são realizados os contratos (“combinados”) e as regras não negociáveis, regidas quando estritamente necessário e que diz respeito aos princípios de justiça, saúde e segurança, por exemplo. Parece que o "combinado" que as professoras fazem com as crianças é, na verdade, estabelecer uma regra imutável e superior. Piaget (1994) explicou que a regra para a criança heterônoma provém da autoridade, ela é superior, inalterável e justa, e, pouco a pouco, torna-se alterável por consenso do grupo e não mais imposta pela autoridade. Observa-se que as professoras desta pesquisa mantêm e persistem no "combinado" imposto e inalterável, limitam-se em impor e defender a imutabilidade da regra, respostas de sujeitos heterônomos, de acordo com Piaget (1994).

Pertencente à categoria "merecimento" tem-se 23,1\% das justificativas das professoras, e estas priorizam, além do combinado, a questão do merecimento, ou seja, não ficam restritas somente à regra, mas a ampliam valorizando
1 Uma professora respondeu "não sei" e sua resposta não foi computada como resposta certa e nem errada, mas esta "tentou" justificar dentro da categoria "combinados". Se sua resposta fosse considerada errada, somaria $88,4 \%$

2 11,1\% justificaram na categoria "não sei", "porque sim" ou "porque não" e foram descartadas. 
qualitativamente o desempenho de quem ganhou o concurso e, assim, agem com justiça. Para elas, é importante cumprir o dever (o combinado), mas também é importante respeitar o direito da criança. Para La Taille (2006b), valorizar e respeitar os direitos da criança é importantíssimo para a fase do despertar do senso moral da criança pequena, pois permitirá, mais tarde, consolidar o senso de justiça. Todavia, sem deixar de considerar essa virtude, concebida como a mais racional de todas, o autor diz que as crianças pequenas compreendem melhor a generosidade do que as regras atinentes à justiça (LA TAILLE, 2006b, p. 120). Por isso, foi assinalada a importância da virtude generosidade ao professor de educação infantil, pois, inclusive, ela é cronologicamente, do ponto de vista moral, antecessora à justiça para as crianças pequenas, segundo La Taille (2006a).

Tivemos também, entre o grupo de professores que consideram errada a atitude da professora da história, respostas na categoria "sem sentimento", envolvendo três tipos de argumentação que poderiam pertencer à categoria "combinados”, mas ela foi categorizada separadamente, pois, além dessas justificativas priorizarem as regras e o combinado do concurso, elas se diferenciam em desconsiderar os sentimentos da criança que chora. Essas respostas são de professoras do Jardim I, que lecionam para crianças de quatro anos de idade e foram do gênero: "não agir pela emoção", "sem problemas pessoais" e "nada a ver que sumiu", totalizando 11,5\%. "Não agir pela emoção" é um exemplo de resposta que a professora justifica ao julgar como errado a ação da professora da história. Para essa professora, as emoções não devem influenciar as decisões das professoras e agir racionalmente é a melhor forma e a mais justa para resolver os dilemas dentro da sala de aula. "Sem problemas pessoais" também é uma resposta dada para justificar que se as regras foram estipuladas, devem ser cumpridas. Essa professora se embasa em agir com coerência em sala de aula. "Nada a ver que sumiu" é outra resposta que justifica o julgamento da ação da professora. Essa resposta prioriza o que foi combinado sobre o concurso, justificando que as outras crianças não podem ficar prejudicadas com o cachorro que sumiu da 
outra menina. Para esta professora, o grupo e a menina que fez o desenho mais bonito não se relacionam com o sumiço do cachorro e a tristeza da outra menina.

Nota-se que, diante dessas respostas, o afeto e o particular devem ficar fora da escola e, caso apareçam, devem ser ignorados. Visto por esse ângulo, essas professoras perdem a oportunidade da discussão e da reflexão em grupo. Um acontecimento que parece banal pode ser uma oportunidade de todos se colocarem no lugar da colega de classe; da menina que fez o desenho mais bonito não dar tanta importância a um prêmio e sim à dor de uma colega; da professora e das crianças aprenderem a escutar as histórias de perdas e superação de todos da sala de aula; de todos da sala de aula pensarem e se envolverem para achar o cachorro da menina triste; enfim, muitos poderiam ser os aprendizados de um simples fato que essas professoras não deram valor. Segundo Tognetta (2003), a escola centrou-se nos conteúdos do mundo e sobre os objetos da cultura, mas se esqueceu da dimensão afetiva. Explica a autora:

Talvez, também, esse "esquecimento" aconteça devido à falta de consciência de causas que provocam os conflitos nas relações interpessoais, o desconhecimento dos mecanismos de construção psicológica dos sujeitos, intrapessoais e, ainda, o que temos como pior, o desconhecimento de formas adequadas de atuação. (Tognetta, 2003, p. 107)

O autor salienta que "falar de sentimentos favorece sua manifestação, bem como a reflexão sobre os estados de ânimo e as relações intrapessoais que podem provocá-los, amenizá-los ou acentuá-los" (TOGNETTA, 2003, p. 107). Segundo Tognetta e Vinha (2007), os professores dedicam grande parte da aula a problemas relacionados às relações interpessoais; portanto, ignorá-los não seria a melhor solução.

Em relação às justificativas das crianças que consideram a atitude da professora errada, na categoria "merecimento" foram constatadas $16,7 \%$ das justificativas das crianças explicando que o prêmio deve ir para quem fez o desenho mais bonito, ou seja, quem mereceu e ganhou o concurso, sendo direito seu. Verifica-se que as crianças do $1^{\circ}$ ano, com idade 
de seis anos, correspondem ao maior número de respostas, com $26,7 \%$ delas. Algumas respostas das crianças dessa categoria: "Porque ele fez o desenho mais bonito"; "Porque ela (a professora) gostou do seu desenho"; "Porque esse (André) aqui que fez o certo... Ele fez o desenho mais bonito”. É importante mencionar o sentimento de indignação em crianças pequenas citado por La Taille (2006b), quando estas sentem que um direito seu foi violado. Parece que estas crianças já começaram a sentir que a criança da história tem o direito de receber o prêmio porque fez o desenho mais bonito, por isso ela merece ganhar o concurso.

A categoria "resposta difusa" engloba as respostas do tipo "não sei" ou "porque sim", "porque não" e a categoria "outras respostas" abrange as respostas que não tem correspondência com a história contada, como "porque ele tinha medo de bicho papão”. Essas categorias foram descartadas, pois elas não representam e nem revelam a organização do pensamento da criança, como nas categorias que caracterizam as crenças desencadeadas, o que é explicado por Delval (2002), que são as respostas em que as crianças revelam sua organização de pensamento.

Em relação a outros julgamentos, somente uma professora do jardim II não quis se posicionar e respondeu que a professora da história não estava nem certa e nem errada. Das professoras que consideram a ação da professora certa, tem-se $11,5 \%$, duas delas, justificando por meio da categoria "sentimento", decidem dar o prêmio para a Júlia pensando nos sentimentos da criança que chora, sem discutir com as crianças sobre sua decisão. E somente uma professora menciona que pensar nos sentimentos da criança que sofre e conversar com a que ganhou o concurso para doar seu prêmio poderia ser uma boa decisão, ou seja, ela acha importante incentivar e valorizar a criança a se colocar no lugar do colega que sofre, fazendo-a perceber que o prêmio é interessante, que ela mereceu e que a professora agiu com justiça, mas também considera importante agir com generosidade, pensando em seus pares, e fazer bem a eles pode ser melhor ainda. Parece que essa professora tenta trabalhar a simpatia entre as crianças, pois, segundo La Taille (2006b), a simpatia é a “capacidade 
de sentir o que outrem sente [...] e que julgamos digno de despertá-la" (LA TAILLE, 2006b, p. 114-116). Entende-se que essa professora faz a criança que ganhou o prêmio superar, via autoridade, regras além das exigências e sanções, levando-a a entender que as regras não são somente proibitivas (como não bater e não xingar), mas também dizem respeito ao bem-estar alheio.

Em relação às crianças, verifica-se que 72,2\% delas julgam certa a ação da professora da história. Diante desse resultado, perguntamos: pode-se concluir que a maioria das crianças dá mais valor à virtude generosidade do professor em vez da justiça, já que optam pela professora que agiu por generosidade? Acreditamos que sim. Por outro lado, por terem idade entre quatro e seis anos, portanto, bem pequenas, não seria muito difícil a elas falarem que a professora fez algo errado? Isso não poderia significar agir em oposição à obediência à autoridade? Não seria por conta disso que a maioria das crianças responde que a professora fez certo, independentemente de se ela agiu por generosidade ou por justiça? Cremos que sim, também, pois, segundo Piaget (1994), as crianças veem as professoras como superiores e, portanto, suas regras são consideradas sagradas, eternas e imutáveis, e julgar que a professora fez algo errado seria considerado uma transgressão às regras da autoridade. Mas, antes de mostrar a hipótese quanto a essas questões, é necessário verificar as justificativas das crianças. Foi constatado que, na categoria "perda", 14,4\% das justificativas das crianças se referem à perda do cachorrinho, levando em conta somente a consequência do ocorrido, e não o que a criança sente. São exemplos de respostas: "Porque ela perdeu o cachorro"; "Porque ela perdeu o cachorrinho e ele era muito bonitinho". Piaget (1994) diferencia o julgamento por responsabilidade objetiva, que considera mais importante as consequências da conduta, do julgamento por responsabilidade subjetiva, que considera mais as intenções da ação. Assim, para este autor, a criança pequena ignora as intenções de uma ação e julga mais pelos resultados e pelas consequências materiais, o que é confirmado pelos dados desta pesquisa. Em outra categoria, $40 \%$ das respostas das crianças enfatizaram o 
"sentimento" justificando que a professora agiu pelo sentimento que ela possui pela criança que estava chorando por estar triste. Alguns exemplos de respostas das crianças: "Porque ele tava triste"; "Pra ele não ficar triste"; "Porque ele tava muito triste"; "Porque ela tava chorando por causa do cachorrinho dela". Para La Taille (2006b), sensibilizar-se pela dor alheia, portanto, sentir compaixão por outrem, é um dos ingredientes que motiva ações generosas, sentimento experimentado por crianças bem pequenas.

O que esses dados mostram é que parece que a maioria das crianças sente compaixão pela criança da história, pois mencionam que o sofrimento da criança que perdeu seu cachorrinho é motivo para que a professora dê o prêmio a ela. Vale e Alencar (2008), em sua pesquisa sobre generosidade e interesse próprio, obtiveram $90 \%$ dos participantes de 7 anos, $60 \%$ de 10 anos e $90 \%$ de 13 anos decidindo pela virtude generosidade em relação ao interesse próprio. Para as autoras, o alto índice pela generosidade por crianças de 7 anos decorre do que elas imaginam que a autoridade gostaria que fizessem, ou seja, agem pela obediência à autoridade. Será que os nossos resultados dizem algo semelhante? A maioria das crianças optou pela generosidade por obediência à autoridade? Piaget (1994, p. 154) afirmou: "Certamente, as relações da criança com os pais não são apenas relações de coação. Há uma afeição espontânea que impele a criança, desde o princípio, a atos de generosidade e mesmo de sacrifício”. E continuou, "parece haver alguma coisa que conduz a criança a considerar a generosidade recíproca como superior a qualquer sanção" (PIAGET, 1994, p. 172). Temos também La Taille (2006a), que considera que "a generosidade não somente é virtude presente no início da gênese da moralidade, como é mais bem assimilada e, portanto, integrada à consciência moral, do que a justiça nesta mesma fase do desenvolvimento" (LA TAILLE, 2006a, p. 16).

Diante desses argumentos, acredita-se que a maioria das crianças elegeu a generosidade do professor pelos dois motivos explanados: pode ser que elas ajam ainda por obediência à autoridade, mas também, pode haver algo a mais que a coação na relação das crianças com o professor, pois a crian- 
ça pequena, em razão do realismo moral, ainda confunde o seu eu com o eu dos mais velhos, mas já começa a perceber outras necessidades (PIAGET, 1932/1994). Possivelmente, se poderia dizer que o sentimento de compaixão coexiste com a submissão à autoridade nos julgamentos da maioria das crianças desta pesquisa.

Por outro lado, e de modo geral, a maioria das professoras considera que a melhor maneira de agir com as crianças é seguir e "cumprir o combinado". Esse tipo de discurso pode significar que os adultos querem mostrar para as crianças que seguir as regras impostas por eles significa estabelecer uma relação de confiança com as crianças, pois, segundo La Taille (2006b, p. 113), “a confiança em outrem é sentimento importante no início do desenvolvimento moral”. Algumas professoras também se preocuparam com o sentimento de confiança; S25, por exemplo, disse: "Não, de modo algum, a professora fez errado, porque ela tem que ser coerente com o que ela tá falando". Ainda segundo La Taille (2006b), a criança pequena está bem atenta às qualidades das pessoas, e confiar nas figuras de autoridade que pretendem ser sua referência moral implica pensar que a relação de confiança da criança com a autoridade é condição necessária, primeiro para confiar em alguém e, posteriormente, para merecer a confiança de outrem.

Dessa forma, parece-nos que as professoras estão mais preocupadas em cumprir regras para agir com justiça; mas esse limitado cumprimento à regra do concurso somente favorecerá, aos olhos das crianças, a relação de heteronomia existente e dificilmente as mesmas conseguirão agir com autonomia se essa relação de submissão à autoridade persistir. Por outro lado, a maioria das crianças justifica que agir pelo sentimento a alguém é certo; assim, elas apresentam os indícios da compaixão que são um dos ingredientes para se agir generosamente.

Nesta seção passamos a descrever os julgamentos e as justificativas das professoras e das crianças quando perguntamos às primeiras se fossem elas mesmas a agir e às crianças se fossem suas professoras (Perguntou-se: "E se fosse você?" - para as professoras; e "E se fosse a sua professora? Ela ia dar o prêmio para quem? Por quê?” - para as crianças). 
Essas questões levantam representações de si, no caso das professoras, e das professoras, no caso das crianças. Foram usadas "representações" no plural, porque, segundo La Taille (2006b), são muitas as imagens e interpretações que temos de nós, e dos outros também, e podem ser até contraditórias.

Em relação às professoras, observa-se que $61,5 \%$ optaram pela protagonista que premia quem fez o desenho mais bonito, pretendendo, assim, agir com justiça; $26,9 \%$ acham que a melhor atitude é compartilhar o prêmio, ou seja, dividir ou conversar para as duas crianças dividirem o prêmio; e somente $7,7 \%$ delas acharam que deveriam agir conforme a protagonista da história, dando o prêmio para a menina que estava chorando e agir com generosidade.

Quanto à maioria das professoras que optou pela justiça, 53,8\% justificaram que o prêmio deveria ir para quem ganhou o concurso por merecimento. Das que justificaram pela generosidade e por compartilhar, verificou-se que $23,1 \%$ das professoras dariam o prêmio para a menina que perdeu o cachorro por sentimento à criança que está triste, ou seja, acham importante perceber as necessidades da criança e se sensibilizam com essa situação.

Segundo as imagens que as crianças têm do professor, $77,8 \%$ acham que o professor dará o prêmio para quem fez o desenho mais bonito e agirá com justiça e $22,2 \%$ acham que o professor dará o prêmio para a menina que está chorando, por sentimento a ela, e agirá com generosidade. Das justificativas das crianças que acreditam que a professora agirá com justiça, 51,1\% acham que a professora dará o prêmio para quem ganhou o concurso por merecimento, com a resposta: "Porque ela fez o desenho mais bonito". E das crianças que acreditam que a professora agirá com generosidade, somente $14,4 \%$ acham que por sentimento à criança, por ela estar triste é que a professora se sensibilizará a dar o prêmio à criança, com a resposta: "Porque ela estava triste e chorando"; "Porque ele perdeu o cachorrinho e estava chorando". Observa-se que entre as crianças não aparece a categoria "compartilhar", como nas respostas das professoras, talvez pela dificuldade em coordenar perspectivas, aquisição alcançada após a descentração da criança (PIAGET, 2011). 
Em relação à primeira questão do dilema, a maioria das professoras $(84,6 \%)$ se baseia na justiça e, nesta questão, 61,5\% julgam que agiria segundo a justiça. Verifica-se que há mais professoras que julgam os atos do protagonista (primeira questão) que professoras que julgam seus próprios atos baseados na justiça. Provavelmente, essas professoras acham que agir segundo a justiça é a forma ideal de conduzir as situações em sala de aula e, dessa forma, também julgam que seus atos devem se basear pela justiça, mas em menor proporção. Para Tognetta (2009b), quando se remete a uma imagem ideal ao outro, projeta-se no outro a perfeição e, quando essa idealização acontece, procura-se agir semelhantemente para também ser admirado, disse a autora "pode-se aspirar a uma imagem ideal enquanto um valor no qual se projetam os esforços para atingi-lo e tê-lo na própria escala de valores. Em outro sentido, é uma imagem ideal exatamente porque preserva aqueles valores que se tem e que se conserva" (TOGNETTA, 2009b, p. 181).

E em relação à primeira questão do dilema a maioria das crianças julgou que a professora estava certa em agir por sentimento à criança que estava triste, entretanto, quando se pensa segundo as imagens que tem de seus professores (E se fosse a sua professora?), a maioria das crianças julga que estes darão o prêmio para quem fez o desenho mais bonito e agirão com justiça, pelo princípio do merecimento. Pode ser que esses dados mostrem uma típica resposta da relação entre as crianças pequenas e os adultos: as crianças, tendo idades entre quatro e seis anos, manifestam a relação heterônoma estabelecida entre eles, pois, quando perguntamos diretamente como seu professor agirá, sabem perfeitamente o que os adultos exigem como ação moral. Diz Piaget (1994, p. 154):

A obrigação de dizer a verdade, de não roubar, etc. tantos deveres que a criança sente profundamente, sem que emanem de sua própria consciência: são ordens devidas ao adulto e aceitas pela criança. Por consequência, esta moral do dever, sob sua forma original, é essencialmente heterônoma. O bem é obedecer a vontade do adulto. 
Assim, de forma geral, a maioria das professoras acha que agirá conforme a justiça e o mesmo acontece com a maioria das crianças segundo a imagem que têm de seus professores. Houve concordância entre as respostas das crianças e as das professoras em relação a dar o prêmio para quem ganhou o concurso por merecimento.

Dessa forma, os dados, segundo as professoras, estão de acordo com a primeira questão do dilema, mas os dados das crianças não. Na primeira parte da história, as crianças julgaram que a professora que agiu por generosidade era a certa; mas, na segunda parte, quando questionamos como se a protagonista da história fosse a professora delas, elas julgaram que esta daria o prêmio para quem fez o desenho mais bonito porque assim o mereceu - agindo, portanto, só pela justiça. Como analisar essas diferenças? Acreditamos que a forma das perguntas pode ter levado a essas diferenças de respostas. Na primeira pergunta, questionamos: Você acha certo ou errado? As opções foram dadas e as crianças julgaram a partir delas. Sabe-se que julgar uma professora é bem difícil para as crianças em razão da obediência à autoridade, e havia a coexistência do sentimento de compaixão da criança por outra que está triste. Na segunda questão (E se fosse a sua professora, ela daria o prêmio para quem?), tanto a justiça existe como necessidade para a criança (PIAGET, 1994), como a criança sabe que seus professores usam a justiça, e nela o mérito, em seus julgamentos, e, assim, julgam como acreditam que seus professores gostariam que fizessem.

Portanto, pode-se inferir que as imagens que a criança tem do professor lhes possibilita dizer algumas das ordens e das regras que este lhes dá e a forma como lhe impõe o valor de justiça. E, segundo as imagens que as professoras têm delas mesmas, também se pode verificar como o agir com justiça e ser justa com as crianças corresponde à imagem ideal que elas almejam. Dessa forma, pode-se dizer que as professoras veem a virtude de justiça como a forma mais correta e desejada de agir na sociedade; parece que é por meio desta virtude que elas sentem seu valor. 


\section{CONSIDERAÇÕES FINAIS}

A generosidade, colocada lado a lado com a justiça numa história hipotética, não foi virtude valorizada pelas professoras tanto quanto o foi pelas crianças. Embora na história utilizada, como num dilema, os participantes tivessem que julgar pela escolha de uma entre as duas virtudes apenas, intrigou-nos o fato de os professores considerarem pouco espaço para a generosidade, ou o cuidado com os sentimentos dos envolvidos, e enfatizarem, sobremaneira, o cumprimento da regra ou do "combinado".

Acreditamos que, por a generosidade ter sido relacionada ao cuidar na educação infantil, essa virtude pode ajudar o professor de educação infantil a perceber as necessidades menos aparentes da criança que, muitas vezes, não consegue expor seus desejos e dificuldades com clareza. Como autoridade em sala de aula, pensamos que, por meio do ato do cuidado permeado pela virtude generosidade, o professor ajudará a criança a desenvolver sentimentos morais, sociais e intelectuais no respeito aos outros, bem como por si mesma. Diante disso, para cuidar é preciso um comprometimento do professor com a criança em todos os seus aspectos. Ele necessita compreender o que ela sente e pensa, o que traz consigo, a sua história e os seus desejos.

Dessa forma, trabalhar a generosidade na escola, virtude fruto do sentimento de simpatia, possibilitará à criança, primeiramente, sensibilizar-se perante seus pares e, em seguida, abrir-se para construção de outras virtudes, como a solidariedade, a cooperação e mesmo as formas mais elaboradas da justiça. Portanto, é função dos adultos cuidar das crianças e ensiná-las que o cuidado as engrandece como cidadãos capazes de se comover com a dor e as necessidades alheias; que o cuidado provoca o envolvimento afetivo com outrem e, assim, permite ao homem ser capaz de condutas generosas e solidárias. Ao contrário, agir com violência, competir incessantemente para ser "vencedor" ou cometer bullying e humilhar um colega, arruinará essa construção.

Enfim, o cuidado, tão próximo à generosidade, inspirará e ensinará que, para ser moral e ético, o outro faz parte desse crescimento; e agir com generosidade e sentir simpatia pelo 
outro possibilitará a construção do nosso projeto de felicidade - com outrem, para outrem, em instituições justas (RICOEUR, 1990).

\section{REFERÊNCIAS}

ARISTÓTELES. Ética a Nicômaco. Tradução de Mário Gama Kury. 4. ed. Brasília: UnB, 2001.

BRASIL. Lei n. 11.274 de 06 de fevereiro de 2006. Altera a redação dos arts. 29, 30, 32 e 87 da Lei n. 9.394, de 20 de dezembro de 1996, que estabelece as diretrizes e bases da educação nacional, dispondo sobre a duração de 9 (nove) anos para o ensino fundamental, com matrícula obrigatória a partir dos 6 (seis) anos de idade. Brasília, DF, 2006.

CHAUÍ, Marilena. Convite à filosofia. São Paulo: Ática, 2004.

COMTE-SPONVILLE, André. Pequeno tratado das grandes virtudes. Tradução de Eduardo Brandão. São Paulo: Martins Fontes, 1995.

COSTA, Fernando Augusto Bentes de Souza. Representações de si de professores do ensino fundamental: um estudo sobre a virtude do amor. 2007. Tese (Doutorado em Psicologia Escolar e do Desenvolvimento Humano) Instituto de Psicologia, Universidade de São Paulo, São Paulo, 2007.

DELVAL, Juan. Introdução à prática do método clínico: descobrindo o pensamento das crianças. Tradução de Fátima Murad. Porto Alegre: Artmed, 2002.

DIAS, Andrea Cristina Félix. Estudo psicológico sobre o lugar das virtudes no universo moral aos 07 anos de idade: as crianças da $1^{\mathrm{a}}$ série discutem coragem e generosidade. 2002. Dissertação (Mestrado em Psicologia Escolar e do Desenvolvimento Humano) - Instituto de Psicologia, Universidade de São Paulo, São Paulo, 2002.

GILLIGAN, Carol. Uma voz diferente. Rio de Janeiro: Rosa dos Tempos, 1982.

KOHLBERG, Lawrence. Psicologia del desarrollo moral. Bilbao: Desclée de Brouwer, 1992.

LA TAILLE, Yves de. Para um estudo psicológico das virtudes morais. Educação e Pesquisa, v. 26, n. 1, p. 109-121, 2000.

Desenvolvimento moral: a polidez segundo as crianças. Cadernos de Pesquisa, n. 114, p. 89-119, 2001.

A importância da generosidade no início da gênese da moralidade na criança. Psicologia: Reflexão e Crítica, v. 19, n. 1, p. 9-17, 2006 a.

Moral e ética: dimensões intelectuais e afetivas. Porto alegre: Artmed, 2006b.

. Formação ética: do tédio ao respeito de si. Porto Alegre: Artmed, 2009. 
LIMA, Vanessa Aparecida Alves de. A generosidade segundo sujeitos de 6, 9 e 12 anos. 2000. Dissertação (Mestrado em Psicologia Escolar e do Desenvolvimento Humano) - Instituto de Psicologia, Universidade de São Paulo, São Paulo, 2000.

. De Piaget a Gilligan: retrospectiva do desenvolvimento moral em psicologia. Um caminho para o estudo das virtudes. Psicologia: Ciência e Profissão, v. 24, n. 3, p. 12-23, 2004.

LUKJANENKO, Maria de Fátima Silveira Polesi. Um estudo sobre a relação entre o julgamento moral do professor e o ambiente escolar por ele proporcionado. 1995. Dissertação (Mestrado em Educação) - Faculdade de Educação, Universidade Estadual de Campinas, Campinas, 1995.

MARTINS, Raul Aragão. Intenção e consequência no julgamento moral. 1996. Dissertação (Mestrado em Psicologia) - Fundação Getulio Vargas, Rio de Janeiro, 1986.

MONTENEGRO, Thereza. O cuidado e a formação moral na educação infantil. São Paulo: Educ; Fapesp, 2001.

PIAGET, Jean. A representação do mundo na criança. Rio de Janeiro, Record, 1975. (Publicação original de 1926).

. O juízo moral na criança. São Paulo, Summus, 1994. (Publicação original de 1932).

. Seis Estudos de Psicologia. Tradução de Maria Alice Magalhaes D’Amorim e Paulo Sergio Lima Silva. 25. ed. Rio de Janeiro: Forence Universitária, 2011. (Publicação original de 1964).

PINHEIRO, Viviane Potenza Guimarães. A generosidade e os sentimentos morais: um estudo exploratório na perspectiva dos modelos organizadores do pensamento. 2009. Dissertação (Mestrado em Educação) - Faculdade de Educação, Universidade de São Paulo, São Paulo, 2009.

RICOEUR, Paul. Soi-même comme um autre. Paris: Édicion Du Seuil, 1990.

SOEJIMA, Fatima Mitie. Educação e formação humana: uma discussão sobre o conceito de autonomia discente. 2008. Dissertação (Mestrado em Educação) - Faculdade de Educação, Universidade de São Paulo, São Paulo, 2008.

SPSS. IBM SPSS Statistics for Windows v.20.0. Chicago: SPSS Inc., 2011.

TOGNETTA, Luciene Regina Paulino. A construção da solidariedade e a educação do sentimento na escola: uma proposta de trabalho com as virtudes numa visão construtivista. Campinas: Mercado de Letras, 2003.

. As virtudes morais no cenário da modernidade. In: TOGNETTA,

L. R. P. (Org.) Virtudes e educação: o desafio da modernidade. Campinas: Mercado de Letras, 2007. p. 9-15.

. A formação da personalidade ética: estratégias de trabalho com afetividade na escola. Campinas: Mercado de Letras, 2009a.

Perspectiva ética e generosidade. Campinas/São Paulo: Mercado de Letras, 2009b. 
TOGNETTA, Luciene Regina Paulino; ASSIS, Orly Zucatto Mantovani de. A construção da solidariedade na escola: as virtudes, a razão e a afetividade. Educação \& Pesquisa, São Paulo, v. 32, n. 1, 2006.

TOGNETTA, Luciene Regina Paulino; VINHA, Telma Pileggi. Quando a escola é democrática: um olhar sobre a prática das regras e assembleias na escola. Campinas: Mercado de Letras, 2007.

VALE, Liana Gama. Desenvolvimento moral: a generosidade sob ótica de crianças e adolescentes. 2006. Dissertação (Mestrado em Psicologia) Centro de Ciências Humana e Naturais, Universidade Federal do Espírito Santo, Vitória, 2006.

VALE, Liana Gama; ALENCAR, Heloisa Moulin de. Generosidade versus interesse próprio: juízos morais de crianças e adolescentes. Psicologia: Teoria e Pesquisa, Brasília, v. 24, n. 4, p. 423-431, 2008.

\section{ROSANA AKEMI KAWASHIMA}

Doutora em Educação pelo Programa de Pós-Graduação em Educação da Faculdade de Filosofia e Ciências da Universidade Estadual Paulista “Julio de Mesquita Filho" (Unesp) rosana_akemi@hotmail.com

\section{RAUL ARAGÃO MARTINS}

Doutor em Psicologia pela Fundação Getúlio Vargas (FGV-RJ). Professor adjunto do Departamento de Educação do Instituto de Biociências, Letras e Ciências Exatas da Universidade Estadual Paulista "Júlio de Mesquita Filho" (Unesp) raul@ibilce.unesp.br 